\title{
Erratum to: Public Key Cryptography - PKC 2009
}

\author{
Stanisław Jarecki and Gene Tsudik \\ University of California, Irvine, Computer Science Department, \\ Irvine, CA 92697-3435, USA \\ \{stasio,gts\}@ics.uci.edu
}

\section{Erratum to: \\ S. Jarecki and G. Tsudik (Eds.) \\ Public Key Cryptography - PKC 2009 \\ DOI: $10.1007 / 978-3-642-00468-1$}

The book was inadvertently published with an incorrect name of the copyright holder. The name of the copyright holder for this book is: (c) Springer-Verlag Berlin Heidelberg. The book has been updated with the changes.

The updated original online version for this book can be found at DOI: $10.1007 / 978-3-642-00468-1$ 